\title{
Application of the Supercapacitor for Energy Storage in China: Role and Strategy
}

\author{
Yanchun Yang ${ }^{1}$, Yinghui Han ${ }^{2,3, * \mathbb{D}}$, Wenkun Jiang ${ }^{2,3}$, Yuyang Zhang ${ }^{4}$, Yanmei $\mathrm{Xu}^{3}$ \\ and Ayman Mahmoud Ahmed ${ }^{5}$
}

check for updates

Citation: Yang, Y.; Han, Y.; Jiang, W.; Zhang, Y.; Xu, Y.; Ahmed, A.M. Application of the Supercapacitor for Energy Storage in China: Role and Strategy. Appl. Sci. 2022, 12, 354. https://doi.org/10.3390/ app12010354

Academic Editor: Luisa F. Cabeza

Received: 10 November 2021

Accepted: 14 December 2021

Published: 30 December 2021

Publisher's Note: MDPI stays neutral with regard to jurisdictional claims in published maps and institutional affiliations.

Copyright: () 2021 by the authors. Licensee MDPI, Basel, Switzerland. This article is an open access article distributed under the terms and conditions of the Creative Commons Attribution (CC BY) license (https:/ / creativecommons.org/licenses/by/ $4.0 /)$.
1 China Energy Longyuan Environmental Protection Co., Ltd., Beijing 100039, China; yanchun.yang.d@chnenergy.com.cn

2 College of Resources and Environment, University of Chinese Academy of Sciences, Beijing 101408, China; WenkunJiang@ncepu.edu.cn

3 Department of Mathematics and Physics, North China Electric Power University, Baoding 071000, China; xuyanmei@ncepu.edu.cn

4 School of Electrical Engineering and Telecommunications, University of New South Wales, Sydney 2052, Australia; yuyang.zhang1@unswalumni.com

$5 \quad$ Space Imaging Department, Egyptian Space Agency, Cairo 11926, Egypt; ayman.ahmed@egsa.gov.eg

* Correspondence: yinghuihan@ncepu.edu.cn

\begin{abstract}
Supercapacitors are widely used in China due to their high energy storage efficiency, long cycle life, high power density and low maintenance cost. This review compares the differences of different types of supercapacitors and the developing trend of electrochemical hybrid energy storage technology. It gives an overview of the application status of supercapacitors in China's smart grid and Energy Internet in detail. Some strategies and constructive suggestions are put forward to solve the existing problems. With the improvement of the grid-connected capacity of new energy power generation during the 14th Five-year Period of China, the supercapacitor market in China will usher in a good development opportunity. The role of the supercapacitor in achieving carbon peak carbon neutralization is prospected.
\end{abstract}

Keywords: supercapacitor; short-term high-frequency energy storage; grid connected; energy efficiency; smart grid

\section{Introduction}

With the depletion of traditional fossil energy and the rapid deterioration of the environment, new energy technology is receiving worldwide attention and eliciting widespread interest. However, new energy generation has the inherent deficiencies of randomness, volatility and intermittence. After a high proportion of new energy is connected to the power system, the conventional power supply should not only follow the load change, but also balance the output fluctuation of the new energy. However, China's power supply is mainly thermal power, accounting for $73 \%$ in 2021, while the proportion of the flexible power supply, such as pump storage and gas power, is low, and the peak-frequency modulation is limited. Due to its flexible charging-discharging characteristics, the electrochemical energy storage system (ESS) is considered one of the practical tools to enhance power quality and energy efficiency. It can be applied to solve the randomness and uncertainty of new energy to a large degree. Supercapacitors can bring many advantages, such as high power density, being maintenance-free, high reliability, and no environmental pollution, which make it stand out from other storage technologies. Moreover, supercapacitors can be widely used in many fields, such as electric vehicles, energy power systems, urban rail transit, etc. With the adjustment of China's energy structure and the increasing demand for electrochemical storage power stations, the Chinese supercapacitors market has proliferated in the 13th five-year period. From 2015 to 2020, China's supercapacitor market 
increased from CNY 6.65 billion to CNY 15.49 billon, with a compound annual growth rate of $18.4 \%$. It is predicted that the market size of China's supercapacitor will reach CNY 17.6 billion by the end of 2021 [1]. Demand for the supercapacitor is expected to grow by a 30\% annualized rate for a long time to meet the carbon neutrality targets by 2060 . Benefiting from the increased demand in downstream markets, such as new energy vehicles, the overall market share of the supercapacitors in China will continue to rise. Therefore, it is of great significance to deeply analyze the development strategy of supercapacitors in China's energy structure transformation during the 14th Five-year Plan period and discuss their role in realizing carbon neutrality.

\section{Technology Characterization}

Compared with conventional secondary batteries, electrochemical supercapacitors exhibit a long cycling life and high power density but with low energy density as a highfrequency energy storage device [2]. Table 1 describes the advantages and disadvantages of supercapacitors compared with several common batteries [3,4].

Table 1. Performance comparison between supercapacitors and batteries.

\begin{tabular}{|c|c|c|}
\hline Energy Storage Devices & Advantages & Disadvantages \\
\hline Supercapacitor & $\begin{array}{ll}\text { 1. } & \text { Fast charging speed (less than } 10 \mathrm{~s}) \\
\text { 2. } & \text { Long cycle life (up to } 500,000 \text { cycles) } \\
\text { 3. } & \text { High power density }(300 \mathrm{~W} / \mathrm{kg} \sim 5000 \mathrm{~W} / \mathrm{kg}) \\
\text { 4. } & \text { Wide temperature range }\left(-40{ }^{\circ} \mathrm{C} \sim+70{ }^{\circ} \mathrm{C}\right)\end{array}$ & $\begin{array}{l}\text { 1. } \quad \text { Electrolyte leakage is likely to occur } \\
\text { 2. Low energy density } \\
\text { 3. }\end{array}$ \\
\hline Lithium-ion battery & $\begin{array}{l}\text { 1. The high energy density }(150 \mathrm{Wh} / \mathrm{kg} \\
\text { and rising) } \\
\text { 2. Long service life (charging and discharging } \\
\text { times up to } 5000 \text { times) } \\
\text { 3. Low environmental pollution }\end{array}$ & $\begin{array}{l}\text { 1. Lithium-ion battery electrodes are } \\
\text { expensive } \\
\text { 2. More security risks }\end{array}$ \\
\hline Lead-acid battery & $\begin{array}{ll}\text { 1. } & \text { Output voltage stability } \\
\text { 2. } & \text { Low battery cost } \\
\text { 3. } & \text { Simple maintenance } \\
\text { 4. } & \text { Good battery stability }\end{array}$ & $\begin{array}{l}\text { 1. The low energy density (one third of } \\
\text { lithium-ion batteries) } \\
\text { 2. Short cycle life } \\
\text { 3. The production and waste of batteries } \\
\text { pollute the environment greatly }\end{array}$ \\
\hline Sodium sulfur battery & $\begin{array}{l}\text { 1. Electrode materials are readily available } \\
\text { 2. High-temperature battery (operating } \\
\text { temperature about } 350^{\circ} \mathrm{C} \text { ) }\end{array}$ & $\begin{array}{l}\text { 1. The battery diaphragm is prone to } \\
\text { corrosion and explosion at high } \\
\text { temperatures } \\
\text { 2. The startup time is long } \\
\text { 3. High maintenance costs }\end{array}$ \\
\hline
\end{tabular}

According to the conversion mechanism of electrochemical energy storage, supercapacitors can be classified as double-layer capacitors, pseudo capacitors, and hybrid capacitors [5]. Figure 1 shows several supercapacitor structures. 

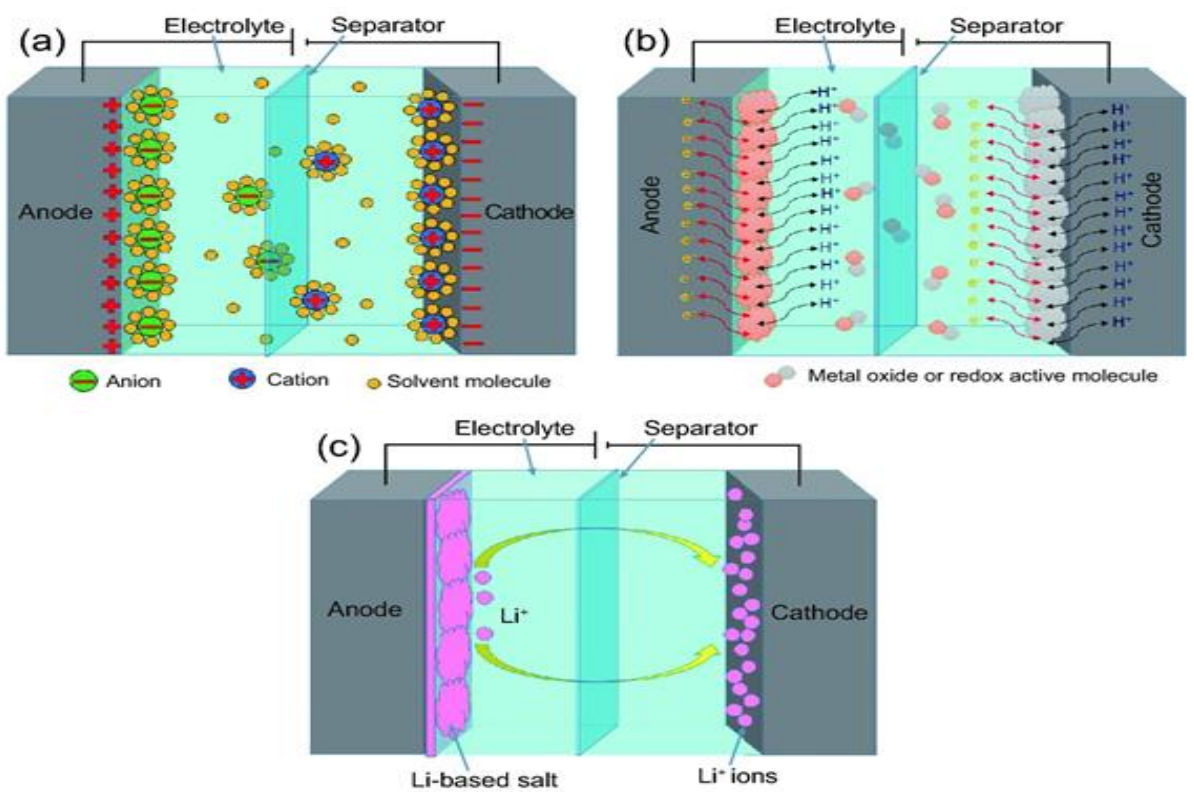

Figure 1. Schematic representation of (a) electrical double-layer capacitor (EDLC), (b) pseudocapacitor (PC) and (c) hybrid supercapacitor (HSC).

\subsection{Double-Layer Supercapacitor}

A double-layer supercapacitor is a kind of supercapacitor based on the interface double-layer theory put forward by German physicist Helmholtz [6]. It is well known that a metal electrode inserted in an electrolyte solution has an excess charge with the opposite sign on both sides of the liquid surface, resulting in the potential difference between phases. The positive and negative ions in the electrolyte rapidly move toward the poles under the action of the electric field and form a tight charge layer (double electric layer) on the surface of the two upper electrodes, respectively. The formed double electric layer is similar to the polarized charge generated by the dielectric in the traditional capacitor under the action of the electric field, resulting in the capacitance effect. Because the distance between layers of charge in supercapacitors is much smaller than that in traditional capacitors, its capacity is much larger than that of traditional capacitors. Compared with the rechargeable battery, the double-layer capacitor can be charged more than $10^{6}$ times. Therefore, the double-layer capacitor not only has the characteristics of a capacitor, but also has the properties of a battery. So, they are sometimes called battery-type capacitors. Poudel et al. used ZMA$\mathrm{LDH} @ \mathrm{Fe}_{2} \mathrm{O}_{3} / 3 \mathrm{DHPCNF}$ as an independent electrode material for supercapacitors [7], which has high capacitance under both positive and negative operating potentials. The composite electrode has an areal capacitance of $3437 \mathrm{~F} \mathrm{~cm}^{-2}$ at $1 \mathrm{~mA} \mathrm{~cm}^{-2}$, providing ultra-high cycle stability. Zhu et al. used the optimized $\mathrm{ZnO} / \mathrm{Co}_{3} \mathrm{O}_{4} / \mathrm{NiO}-2(\mathrm{ZCN}-2)$ as a double-layer supercapacitor electrode, and the electrode showed excellent electrochemical performance [8]. When the current density is $1 \mathrm{Ag}^{-1}$, the specific capacitance of ZCN-2 is $1119.11 \mathrm{C} \mathrm{g}^{-1}$. Under the condition of $10 \mathrm{Ag}^{-1}$, the capacitance can still maintain $93.75 \%$ after 5000 charge-discharge cycles. Its maximum energy density can reach $95.82 \mathrm{Wh} \mathrm{kg}^{-1}$, and the cycle stability can reach $94.53 \%$ of the initial value after 10,000 charge-discharge cycles at the current density of $10 \mathrm{~A} \mathrm{~g}^{-1}$. After charging, the device connected by two supercapacitors can successfully keep light-emitting diodes (LED) glowing for up to $30 \mathrm{~min}$. Zhu et al. directly synthesized $\mathrm{Co}_{2} \mathrm{Mn}$ bimetallic hydroxide nanowire on nickel foam by the hydrothermal method and then prepared $\mathrm{Co}_{2} \mathrm{Al} \mathrm{LDH}$ nanosheets on $\mathrm{Co}_{2} \mathrm{Mn}$ nanowire by the hydrothermal method to obtain heterogeneous nanocomposites $\left(\mathrm{Co}_{2} \mathrm{Al} / \mathrm{Co}_{2} \mathrm{Mn}\right)$ [9]. Using $\mathrm{Co}_{2} \mathrm{Al} / \mathrm{Co}_{2} \mathrm{Mn} / \mathrm{NF} / \mathrm{AC} / \mathrm{NF}$ as nanocomposite material, the performance of the supercapacitor is greatly improved. When the current density is $1 \mathrm{Ag}^{-1}$, the specific capacitance of the nanocomposites can reach $1125.9 \mathrm{Cg}^{-1}\left(2502 \mathrm{Fg}^{-1}\right)$. At a current density of $20 \mathrm{Ag}^{-1}$, its specific capacitance remains $82.53 \%$ of the initial specific capacitance after 
6000 cycles. When the power density is $412.73 \mathrm{~W} \mathrm{~kg}^{-1}$, the energy density of the hybrid supercapacitor can reach $64.58 \mathrm{Wh} \mathrm{kg}^{-1}$.

\subsection{Faraday Pseudocapacitor}

The pseudocapacitors display relatively higher energy density and capacities, owing to the fast and reversible faradic redox reactions of electroactive materials of the electrodes in the range of certain potential on the electrode surface or near the surface. It causes capacitance by fast and reversible surface or near-surface reactions rather than the electrostatic force. The transition metal oxides are being widely studied because of their abundance, easy preparation, and environmentally friendly quality. For example, $\mathrm{NiO}, \mathrm{MnO}_{2}, \mathrm{Co}_{3} \mathrm{O}_{4}$ and $\mathrm{TiO}_{2}$ exhibit good electrochemical performance, owing to their reversible multi-electron redox Faradaic reaction. However, an electrode using a single metal oxide has drawbacks, such as low conductivity and poor cycling stability. Coupled metal cations can contribute to improving the metallic conductivity and electrochemical activity, which are indispensable for pseudocapacitor applications. Binary metal oxides, such as $\mathrm{NiMn}_{2} \mathrm{O}_{4}, \mathrm{NiCo}_{2} \mathrm{O}_{4}$, $\mathrm{MnCoO}_{3}, \mathrm{NiMoO}_{4}$, and $\mathrm{CuCoO}_{4}$, are widely studied. For example, Wang et al. reported that $\mathrm{NiCo}_{2} \mathrm{O}_{4} / \mathrm{N}-\mathrm{rGO}$ nanocomposites exhibited excellent electrochemical performance for pseudocapacitors and these materials can be derived via the solvothermal and hydrothermal methods [10]. $\mathrm{NiCo}_{2} \mathrm{O}_{4} / \mathrm{N}-\mathrm{rGO}$ nanocomposites have high activity, large specific capacitance, and good rate performance as electrode materials for supercapacitors because $\mathrm{NiCo}_{2} \mathrm{O}_{4} / \mathrm{N}-\mathrm{rGO}$ shows a high specific capacitance of $2090 \mathrm{Fg}^{-1}$ at a current density of $1 \mathrm{Ag}^{-1}$. When the current density reaches $10 \mathrm{Ag}^{-1}$, the electrode material still maintains the specific capacitance of $1257.5 \mathrm{Fg}^{-1}$ and the capacitance retention rate is $96.19 \%$ after 5000 cycles. Chavan et al. [11] found that a polycrystalline nanoflake $\mathrm{NiMoO}_{4}$ thin file could be used to prepare electrochromic supercapacitor (smart supercapacitor), which exhibits high specific capacitance up to $1853 \mathrm{~F} / \mathrm{g}$ at a current rate of $1 \mathrm{~A} / \mathrm{g}$ and display remarkable specific capacitance retention of $65 \%$ after 2500 cycles. Han et al. conducted a large number of systematic studies on bimetallic or polymetallic oxide supercapacitors, including $\mathrm{Mn}-\mathrm{Ce}$ [12], Mn-Ni [13], Ce-Ni, Ni-Fe-Sr [14], etc. Bimetallic oxides are generally superior to monometal oxides as pseudocapacitance electrodes. Figure 2 shows various bimetallic or polymetallic oxides electrodes and typical pseudocapacitances. Figure 2a describes the main preparation process of pseudocapacitance electrode materials. Take $\mathrm{Ni}-\mathrm{Fe}$ electrode prepared from nickel-based zeolite capsule complex with $\mathrm{Fe}_{3} \mathrm{O}_{4}$ as an example, this fabrication process is easy to operate and popularize. Ni-Fe pseudocapacitance performs good specific capacitance of $739.8 \mathrm{Fg}^{-1}$ at the current density of $1 \mathrm{Ag}^{-1}$ in a $6 \mathrm{M} \mathrm{KOH}$ solution [15]. Figure $2 \mathrm{~b}$ compares the specific capacitance properties of various pseudocapacitance electrode materials. It can be seen that the average specific capacitance performance of nickel-based bimetallic materials is generally better, which is the main reason why nickel-based pseudocapacitors have attracted much research attention in recent years. However, the performance of polymetallic electrode is not better than that of bimetallic electrode. For example, the specific capacitance of Ni-Fe-Sr trimetal composite electrode is less than half of that of Ni-Fe bimetal composite electrode, and similar results also appear in other metal combinations. Even more noteworthy, strontium-based bimetal oxides $\left(\mathrm{Sr}_{\mathrm{x}} \mathrm{M}_{\mathrm{y}} \mathrm{O}_{\mathrm{z}}\right.$, where $\mathrm{M}$ is any metal) possessing excellent metallic properties and show immense potential for pseudocapacitances. Han et al. systematically studied the properties of strontium-bismuth bimetallic oxides as pseudocapacitances, theoretically and experimentally. Figure $2 \mathrm{c}$ shows that a flexible strontium-bismuth bimetallic oxides symmetric pseudocapacitance has high specific capacitance of $1228.7 \mathrm{Fg}^{-1}$ at a current density of $1 \mathrm{Ag}^{-1}$ and good cycling performance of $80.11 \%$ over 2000 charge-discharge cycles [16]. Figure $2 \mathrm{~d}$ the micro-model and band structure of Sr-Bi bimetallic oxides. When the $\mathrm{Sr} / \mathrm{Bi}$ ratio is 1/3, Sr-Bi bimetallic oxides has a smallest band gap and the most significant hybridization of the electronic density, which is conductive to high capacity charge storage. 

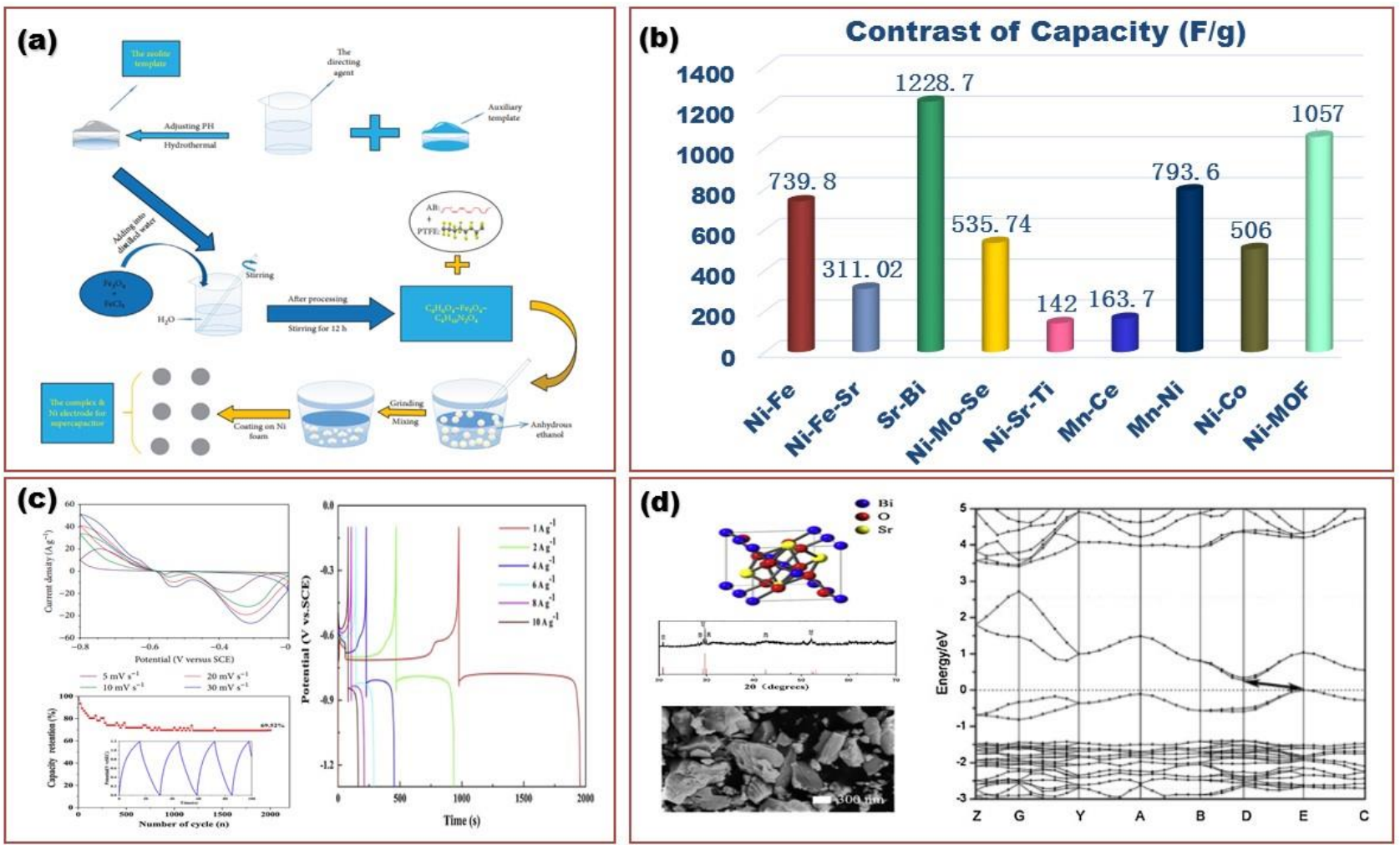

Figure 2. Electrode materials and typical pseudocapacitances. (a) the preparation process of pseudocapacitance [15], Open Access, (b) the contrast of the specific capacitance properties of various bimetallic or multi-metallic oxides pseudocapacitance electrode materials, (c) CV curve, cycling performance, and GCD curves of the Sr-Bi bimetallic oxides pseudocapacitance electrode [16], Open Access (d) Micro-model, XRD pattern, SEM, and band structure of Sr-Bi bimetallic oxides [16], Open Access.

\subsection{Hybrid Supercapacitor}

Hybrid supercapacitors are also known as asymmetric capacitors. Transition metal oxides or conducting polymers are used as their positive materials (energy source) and activated carbon (AC) is used as their negative material (power source). Its charge storage mechanism combines the fast and reversible faradic redox reactions with reversible adsorption of ions of active materials. So, hybrid supercapacitors have relatively high energy density in combination with high specific capacitance, compared with that of Faraday pseudocapacitors and double-layer supercapacitors. It has a wide application in portable supplies, memory backup systems, electric vehicles, and emergency backup power because of their long battery life, higher power density, and smaller volume. Most recently, Yang et al. studied a type of tip-open CNT/CNF hierarchical hybrids via $\mathrm{KOH}$ activation on the CVD-grown $\mathrm{Al} / \mathrm{Fe}$-catalyzed CNT/CNF precursors [17]. It can fully open the CNT hierarchies' tips using $\mathrm{KOH}$ activation under $700-750{ }^{\circ} \mathrm{C}$ for $90 \mathrm{~min}$. The tip-open CNT-CNF hybrids show a highly improved specific capacitance, which increases by 3.3 times that of the pristine ones. Sweep analysis indicated that the diffusion-type capacitance increases by 3.7 times, while the Helmholtz-type capacitance increases only by 1.5 times, indicating that the tip-open CNTs contribute to $30 \%$ of the increase in the double-layer capacitance. A aqueous hybrid supercapacitor (AHSCs) based on the optimized $\mathrm{CoMoO}_{4} / \mathrm{MnO}_{2}$ nanowires/Ni foam (KF-CMNWs) electrode and modified alkali-treated carbon nanotubes film (M-CNTF) with $\mathrm{K}_{3} \mathrm{Fe}(\mathrm{CN})_{6}$ in neutral aqueous $\mathrm{Na}_{2} \mathrm{SO}_{4}$ electrolyte was introduced by Zhang et al. [18]. These AHSC can not only improve the device cycle life by more than 10,000 cycles and $96.8 \%$ capacitance retention, but also a high energy density of $62.9 \mathrm{Wh} \mathrm{kg}^{-1}$ at a power density of $984 \mathrm{~W} \mathrm{~kg}^{-1}$ is demonstrated. 


\subsection{Comparison}

Electrochemical supercapacitors can be divided into the double-layer capacitor, Faraday pseudocapacitor and hybrid supercapacitor. The Faraday pseudocapacitor has a relatively high energy density due to its unique structure. In the same electrode area, the capacity of the pseudocapacitor is 10 or 100 times that of the common double-layer capacitors. Some of its properties are improved but not prominently, and the others are close to those of the double-layer capacitors. Compared with symmetry double-layer capacitors with carbon electrodes, the hybrid supercapacitor has higher operation voltage and energy density, 2 to 3 times capacitance, and can offer a higher power density, which is suitable to offer a large pulse. Table 2 compares the advantages and disadvantages of the three supercapacitors. Generally, double-layer capacitors and pseudocapacitors with a short charging time and high efficiency are well suited to act as rechargeable stand-alone power sources. Although hybrid supercapacitors take longer to charge, their cycle life is shorter and more prone to leakage, so they are not as widely used as pseudocapacitors and double-layer capacitors [19]. Figure 3 visualizes the differences among the three types of supercapacitors. Electric double layer capacitor (EDLC) is one of the most mature technology, and its market share is the highest, but because of its limitation of material and structure, the energy density of EDLC is not high. In contrast, the energy density of the hybrid supercapacitors have an advantage in charging time, cycle life and power density. Pseudocapacitance in all aspects of performances between the above two. In order to balance the dual goals of massive power demand and carbon neutrality achieved by 2060, it uses abundant natural clean energy (such as wind power generation, and photovoltaic power generation) and the current grid to form a multi-energy complementary system, which can effectively reduce carbon emissions. However, the power generation stability of clean energy, such as wind power and solar power is poor, and the integration of new energy into the power grid will have a significant impact on the current power grid. The hybrid capacitor can play the role of frequency regulation and peak regulation in this multi-energy complementary system and enhance the stability of the power grid.

Table 2. Advantages and disadvantages of the three kinds of supercapacitors.

\begin{tabular}{|c|c|c|}
\hline Types of Supercapacitors & Advantages & Disadvantages \\
\hline Double layer supercapacitor & $\begin{array}{l}\text { 1. The operating temperature range is } \\
\text { 2. Wide from }-40{ }^{\circ} \mathrm{C} \text { to }+70^{\circ} \mathrm{C} \\
\text { 3. High power density } \\
\text { 4. High safety } \\
\text { 5. High reliability and long life } \\
\text { 6. Commercialized }\end{array}$ & $\begin{array}{ll}\text { 1. } & \text { Low voltage } \\
\text { 2. } & \text { High cost } \\
\text { 3. } & \text { High self-discharge }\end{array}$ \\
\hline Faraday pseudocapacitor & 1. High energy density & $\begin{array}{ll}\text { 1. } & \text { Low power density } \\
\text { 2. } & \text { Low voltage } \\
\text { 3. } & \text { High cost }\end{array}$ \\
\hline Hybrid supercapacitor & $\begin{array}{l}\text { 1. Wide operating temperature range } \\
\text { 2. High power density } \\
\text { 3. High safety }\end{array}$ & $\begin{array}{ll}\text { 1. } & \text { Industrialization in progress } \\
\text { 2. } & \text { Temperature variation } \\
\text { 3. } & \text { Low power density }\end{array}$ \\
\hline
\end{tabular}




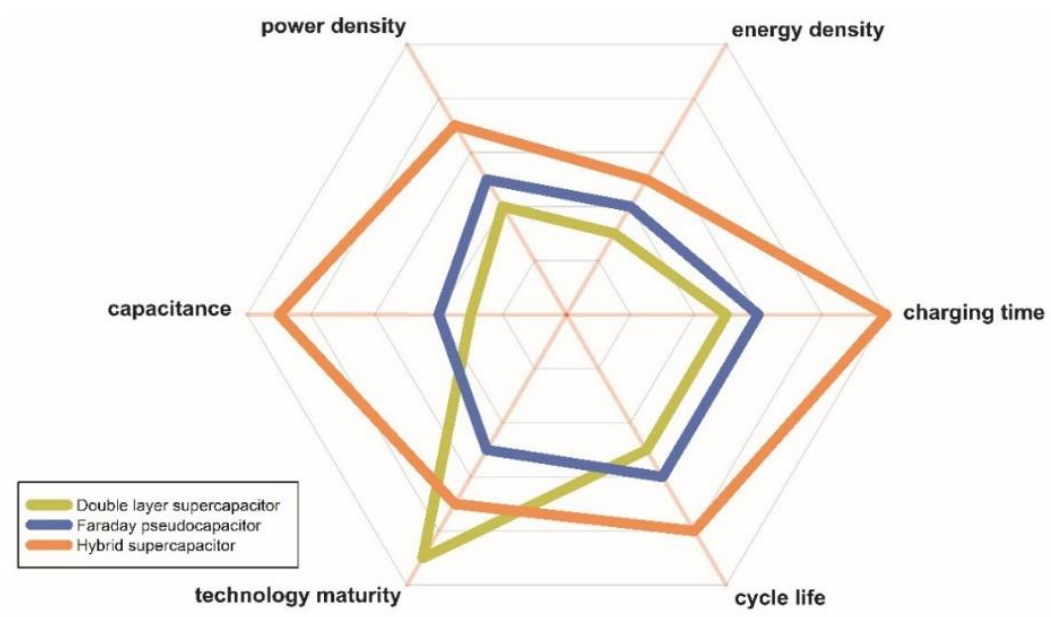

Figure 3. Different characteristics among three types of supercapacitors.

\section{Development of China's Supercapacitor Field}

\subsection{Market Trends, Upstream Materials, and Preparation Procession}

China's demand for supercapacitors is increasing year by year. Figure $4 \mathrm{a}$ shows the comparison of the scale growth of China and the global supercapacitor industry since the 13th Five-year Plan period (2015-2019). In 2020, the China's supercapacitor market scale reached 14.38 billion Yuan, accounting for more than $70 \%$ of the global total, and China has become the largest supercapacitor market in the world, and the growth rate of supercapacitor market in China continues to be higher than the global ones. The upstream field of supercapacitor industry mainly consist of various raw materials, including electrode materials, electrolyte materials, diaphragm, etc. Electrodes and electrolytes are the key materials in the production of supercapacitors, which directly determine the main performance indexes of supercapacitors (such as the energy density, power density, cycle stability, etc.). Activated carbon is the low-cost electrode material with the highest utilization rate among EDLC electrodes. Activated carbon has an abundant pore structure, including micropores (less than $2 \mathrm{~nm}$ ), mesopores $(2 \sim 50 \mathrm{~nm}$ ) and pores larger than $50 \mathrm{~nm}$. It also has the characteristics of a large specific surface area. Although its conductivity is not very outstanding relative to metal oxides $(1250-2500 \mathrm{~S} / \mathrm{m})$, it is still suitable for supercapacitors [20]. Carbon nanotubes have also been widely used in the research of supercapacitor electrodes due to their certain internal network, chemical and thermal strength, and electrical conductivity. Thermal graphene, another ideal electrode material for supercapacitor, has excellent mechanical strength and electrical conductivity, large specific surface area, high carrier mobility, and high chemical stability. In addition, transition metal oxides are redox-active materials that are also widely used in electrode materials. They are usually hybrid supercapacitors that exist in oxide and hydroxide structures. There are many kinds of transition metals, mainly used in the structure of transition metal oxides and various metal hydroxides, namely, nickel, iron, cobalt, titanium, molybdenum, vanadium, and niobium. Transition metal oxide (TMO) is a widely used electrode material. Using this material as the supercapacitor electrode material, the transition metal oxide supercapacitor has higher energy density and power density than that using carbon electrode material. Due to their reversible redox reactions, transition metal oxides (TMO) and conductive polymers (CPs) are widely used in Faraday capacitors. Conductive polymers have high conductivity, photoconductivity, nonlinear optical properties, and magnetic properties. It has the advantages of good flexibility, low production cost, high energy efficiency, large specific surface area, three-dimensional (3D) porous microstructure, and high capacitance energy density and so on. Conductive polymers are coupled with active substances and can be reversibly oxidized or reduced within a certain range. So, conductive polymers are widely used in supercapacitors [21-25]. Supercapacitors can be divided into buttontype, winding-type, and large-type according to their manufacturing process and shape 
structure. The supercapacitors of the three types can be roughly classified as below, $5 \mathrm{~F}$, $5-220 \mathrm{~F}$ and above 200F. Figure $4 \mathrm{~b}$ shows the market share and growth rate of three major types of supercapacitor in China from 2016 to 2020. In 2020, the market size of China's button-type, winding-type, and large supercapacitors was 3.247 billion yuan, 6.937 billion yuan, and 4.196 billion yuan respectively, with a year-on-year growth of $9.58 \%, 8.15 \%$ and 8.62 respectively. Figure $4 \mathrm{c}$ presents the manufacturing process flow chart of soft package supercapacitor. Generally, gases will be generated during the initial formation of supercapacitors, and if gases are not expelled in time, the electrochemical performance will be affected. When the internal air pressure reaches a certain level and the decompression cannot be released in time, explosion may occur. Especially in the soft packaging supercapacitor, the gas generated after complete packaging will be difficult to remove and the safety risk will greatly increase. There is no proper solution to the problem of gas emission in the production process of soft packaging supercapacitor at present. Figure $4 \mathrm{~d}$ illustrates the manufacturing process flow chart of cylindrical supercapacitor. Cylindrical supercapacitors have high production automation level and low manufacturing cost, which can meet different applications. The main disadvantage of this kind of supercapacitor is its poor heat dissipation. When the supercapacitor is charged and discharged at high power, a large amount of heat is generated inside quickly, and the heat dissipation cannot be carried out through thick electrode layer in time. Despite the high efficiency and low power loss ratio of cylindrical supercapacitor, temperature is still an important factor limiting the realization of ultra-high power charge and discharge.
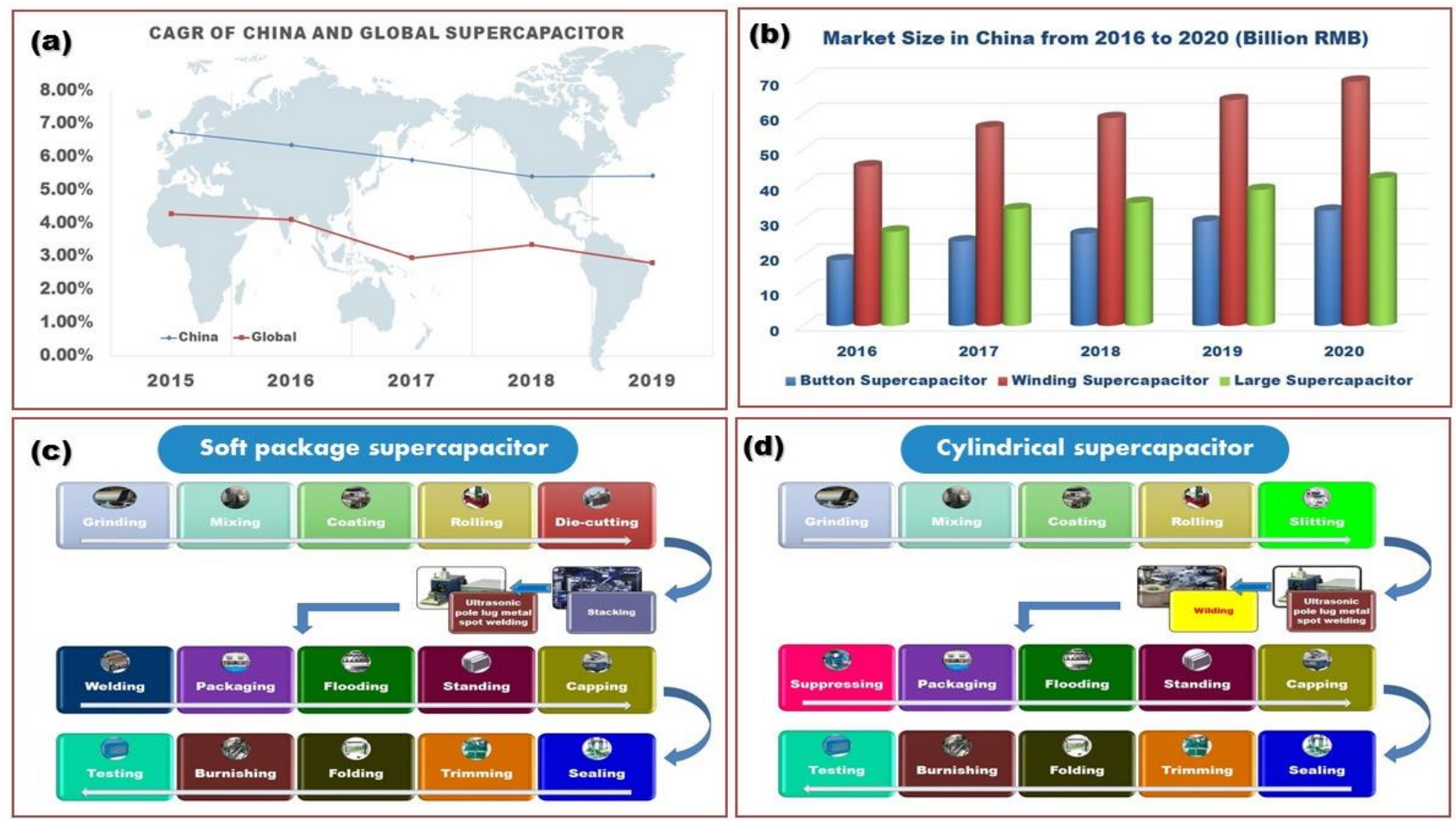

Figure 4. (a) Comparison of the scale growth of China and the global supercapacitor industry, (b) market size of three major types of supercapacitor in China from 2016 to 2020, (c,d) Manufacturing process flow chart of soft package and cylindrical supercapacitor, respectively.

\subsubsection{Electrode Materials}

According to the different types of supercapacitors, the electrode has three forms, i.e., carbon-based electrode, metal oxide electrode, and conductive polymer-based electrode. Carbon material is the most widely used electrode material for supercapacitors at present, mainly because of its wide and stable supply, high specific surface area, good electrical conductivity and chemical stability. The double-layer capacitor composed of carbon mate- 
rial can realize fast charge and discharge and has high power density, but its low specific capacity limits the wide application of the carbon material-based capacitor. An innovative electrode material is developing toward increasing the specific surface area and controllable pore diameter of carbon-based materials, preparing active substances with high specific surface area combined with other metal oxides and discovering different types of conductive polymers with good doping performance. In recent years, the research of novel electrode materials in China has achieved significant development and attained plenty of essential achievements. For example, Zhang et al. [26] found that a supercapacitor prepared with acid-treated graphene has good electrochemical performance, with a maximum specific capacitance of $196 \mathrm{Fg}^{-1}$ at the charge/discharge current density of $100 \mathrm{~mA} \mathrm{~g}^{-1}$ using $2 \mathrm{M}$ $\mathrm{KOH}$ electrolyte, yielding an improvement of $40 \%$ compared with that of the pristine TEGO. Zhai et al. [27] developed a facile method to synthesize a high-quality platinum nanoparticle (PtNP) decorated graphene via one-step $\gamma$-ray induced reduction of graphite oxide (GO) and chloroplatinic acid at room temperature. They found that PtNP can accelerate the electron transfer, increasing the electrochemically active surface area of reduced GO. Han et al. developed a series of bimetallic organic frame electrode materials. The results show that the bimetal skeleton plays a key role in softening the supercapacitor electrode while maintaining and improving the high specific capacitance characteristic of the original metal oxides; its tensile properties and ductility are superior to those of the original bimetal oxides. Meanwhile, they proved that doped or composited multi-walled carbon nanotubes can improve the conductivity in the process of electrode preparation [13].

\subsubsection{Preparation Processes}

The preparation of supercapacitors can be divided into three key steps, i.e., electrode fabrication processing, the monomer structure design, and the control of water-oxygen content. The preparation of electrodes is one of the critical factors affecting its performance index. In terms of electrode preparation methods, Chinese supercapacitor companies are far behind the most advanced ones in the world. The coating technology, which uses styrene-butadiene rubber (SBR) and polyvinylidene fluoride (PVDF) as solvent is widely adopted in China. It has a moderate degree of specific capacity and stability as well as good process ability. Compared with sheet technology from Maxwell Ltd., the leading manufacturer of the supercapacitor, the coating process of China has poor environmental protection and produces relatively more impurities, so its investment is lower. Moreover, the coating technology is dependent on workers' experience and slurry properties fluctuate strongly, which leads to defects prone to low consistency and poor reproducibility. As a result of this, it is an urgent task to solve the process control problem of coating technology for the development of the supercapacitor manufacturing industry in China [28].

The monomer structure design also needs to take into account the current distribution, resistance decrease, electrical contact reliability improvement, and heat dissipation factor and service life. It is the key factor in the preparation to affect the quality of the supercapacitor. The innovative design of the jellyroll structure, including extraction and safe structure, may be the main research direction of monomer structure design to achieve safety pressure release and self-recovery [29]. The control of the water-oxygen content includes the heat treatment of jellyroll and environmental control for electrolyte filling and ball sealing. Water-oxygen content that exceeds the standard causes the monomer voltage to be reduced, resistance to be increased and cycle life to be decreased while assembling supercapacitors. Therefore, the water-oxygen content has to be strictly restricted to $1 \mathrm{ppm}$ in the whole manufacturing process. The control of the water-oxygen content is the shortcoming of China's supercapacitor preparation technology [30].

\subsubsection{Electrolytes}

The electrolyte is an important component influencing the performance of the supercapacitor. The electrolyte can directly impact the performance of the supercapacitor when electrodes remain stable. Electrolytes are classified scientifically into two major categories, 
solid electrolyte and liquid electrolyte. Solid electrolyte can be divided into aqueous electrolyte, nonaqueous electrolyte, and ionic liquid electrolyte. Liquid electrolyte is divided into organic and inorganic [31]. Compared to the nonaqueous electrolyte, the upside of aqueous electrolyte is higher ionic conductivity, lower price, and broader application ranges. The downside is that the former has higher decomposition voltage. The ionic liquid electrolyte is not used widely because of its low conductivity. The development trend of the electrolyte is to find solvents with high solubility, conductivity, and permittivity. In terms of application, Chinese supercapacitor companies mainly use aqueous electrolyte technology, facing great challenges transferring to nonaqueous electrolyte technology in the future. Chinese researchers are exploring the substitution for acrylonitrile (ACN) and the industrialized application of ionic liquid electrolytes [32].

\subsection{Application Status}

The supercapacitor is characterized by high power density, high energy density, long lifetime, and wide temperature range for use, which means that it can be widely used in renewable power integration, peak load shifting, power quality guarantee, and the suppression of low-frequency oscillation in a power system. China had conducted many experiments in the field of microgrid, pitch master power, and energy storage system of the photovoltaic power plant [33-35]. Figure 5a shows the common application of supercapacitors in China. Figure $5 \mathrm{~b}$ shows the market capacities for major application of supercapacitors from 2018 to 2020 in China. Figure 5c shows the market structure of supercapacitor in China in 2020. From the perspective of domestic consumption structure, supercapacitors are widely used in new power grid, wind energy, EV, solar energy, transportation, power energy storage, national defense, and motion control system. The consumption of supercapacitors in transportation and industry accounts for $38.2 \%$ and $30.8 \%$, respectively, that of new energy accounted for $21.8 \%$, and that of equipment and other applications accounts for $9.2 \%$.

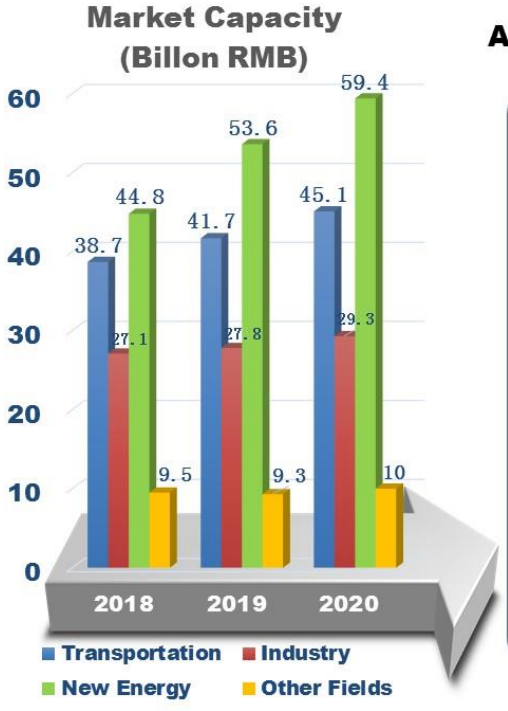

(b)

\section{Application of supercapacitors}

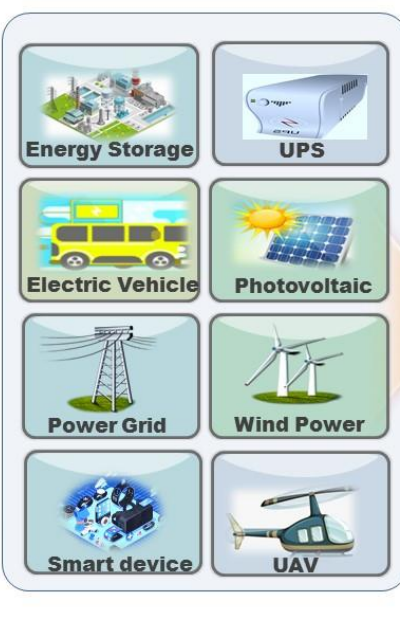

(a)

\section{SUPERCAPACITOR MARKET STRUCTURE (2020)}

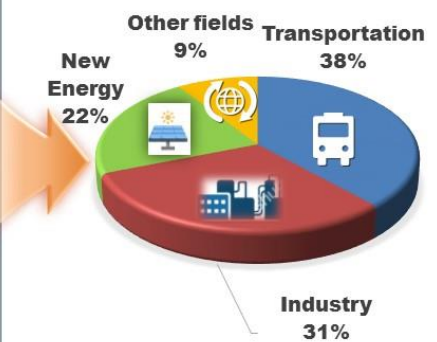

(c)

Figure 5. (a) Application field of supercapacitor. (b) Market segment capacity of supercapacitor from 2018 to 2020 in China. (c) Proportion of consumption structure in China's supercapacitor market in 2020.

\subsubsection{Microgrid}

The microgrid is a complex system involving power, load, energy storage, and control systems. The microgrid works in parallel with the power grid normally. When grid failures occur or the power quality declines, the microgrid is disconnected from the power grid and run independently. In the process of disconnecting, power unbalances and voltage sag often 
happen. The supercapacitor can provide transient sustainment for the microgrid, achieve smooth transition of the two models, and guarantee the microgrid power quality. A study on simulation analyses on the model switch from grid mode to island mode showed that supercapacitors can effectively improve the power quality as well as stability and reliability when a power grid fault occurs and switch into island mode [36].

The output power of micro sources, such as wind and solar energy, is greatly influenced by the environment and is extremely unstable. Due to the benefit of high power density, the supercapacitor can store energy when the load is low. Once the circuit reaches load peak, supercapacitors release the power reserved quickly, which can lead to reducing the impact of transient energy supply problems on the microgrid. Researchers simulated and analyzed the voltage of micro gird with and without supercapacitors, and they found that the supply voltage stability is greatly improved after supercapacitors are operated in the system. China made full use of photovoltaic power generation, wind power, small hydropower, and hybrid energy storage in the Qinghai-Tibet region, which is sparsely populated, and some prefectures and counties are nearly $1000 \mathrm{~km}$ away from the power grid. The researchers have overcome a series of key technical challenges and built a renewable energy power supply system featuring, for example, good power supply quality, strong anti-disturbance capability, high degree of automation, and easy construction and commissioning, which effectively solve the power supply problem in the project application area. Furthermore, microgrid technology has changed mode from laboratory technology to island application [37]. Niusan island, more than $60 \mathrm{~km}$ from Lianyungang, has been transformed into a microgrid with $30 \mathrm{~kW}$ rooftop photovoltaic power generation, $30 \mathrm{~kW}$ diesel generator and lead-carbon battery energy storage to meet the demand of power load for communication equipment, seawater desalination system, air conditioners, refrigerator, and daily lighting. Another island named Nanlu island, adopted wind energy, solar energy, diesel power generation and the battery energy storage integrated wind energy storage distributed power generation system. It uses solar energy and wind energy to store energy through four lithium battery packs and two supercapacitors to ensure a stable power supply while achieving low carbon and low emissions. The supercapacitor as an energy storage device exchanges energy with DC bus of power units, greatly improving the transient sustainability of the microgrid. However, its deficiency lies in the lack of a market operation mechanism, the initial investment following the way of the project, and the lack of market law of the input cost consideration model. Moreover, the whole industry lacks top-level design, and the industrial standard system is not perfect. The distribution of microgrid is relatively dispersed, and the labor cost of operation and maintenance is high [38].

\subsubsection{Wind Power System}

The energy storage device installed in a wind farm is equivalent to constructing a power station with suitable capacity in a wind farm. As the proportion of the installed wind capacity in the total installed capacity increases gradually, when the voltage of the grid connection node in the wind farm drops as a result of power grid failure or disturbance, it has a strong impact on the system stability if cut off the wind farm. For the range of grid voltage drop, the supercapacitor can conveniently provide reactive power for the power grid to avoid the wind turbines being damaged by over-current and thus achieve gridconnected operation, uninterrupted. Ma et al. studied the large capacity energy storage system and its application based on supercapacitor, and they provided the low voltage ride-through solution for wind farms [39]. GCN new energy issued a notice that the group completed the generating capacity of 928.6 gigawatt-hours according to the consolidated statement in January 2020, 12.2\% less than the same period in 2019. According to the 2020 National Economic Statistic Bulletin released by the National Bureau of Statistics, the grid-connected wind power installed capacity reached 281.53 million $\mathrm{kW}$, up $34.6 \%$ from the same period last year.

The wind turbine adjusts the blade angle through a pitch control system to maintain a constant engine speed. The pitch control system must equip backup batteries to shut 
off safety when a major accident happens. The characteristics of the supercapacitor are intermediate, between those of the battery and capacitance. Not only will it reach the capacity of the battery, but it also can operate without maintenance during its service life. Thus, it is very suitable for the environment of the pitch control system. The MW-level supercapacitor solution in the pitch control system is already commercialized in China. The downstream industries of pitch-used supercapacitors have entered the mature stage [40].

\subsubsection{Distribution Automation}

Distribution automation is defined as operation management and fault monitoring based on an automated information system. Distributed systems are exposed to extreme environments, such as lightning strikes, which can cause a power surge that may damage the terminal power supply. Therefore, the distribution automation system must be equipped with a backup power supply to ensure the stability of the distribution network. Because of the wide temperature limit, long service life, free maintenance and the load characteristics of the capacitance, the supercapacitor is a good choice for the design and selection of the power supply. Currently, many companies have proven mature distributed energy storage technologies and many demonstration projects have been launched. The new generation of a distribution automation master station system has realized the real-time data processing from millions to tens of millions of orders, which can improve the dispatching ability to support the operational management level of the distribution network and emergency disposal, and meet the construction and development needs of the regional distributed power supply, microgrid, energy storage, etc. [41,42].

\subsubsection{Communication and Transportation}

The supercapacitor is widely used in electric vehicles (EV). Every time the vehicle is started, the supercapacitor supplies a strong current to the engine to drive its operation, promoting the starting speed of the motor as well as improving the performance of the EV and the state of the battery. As the vehicle brakes, energy recovery and recycling can be achieved easily by supercapacitors. Similarly, as the auxiliary power supply of electric vehicles, supercapacitors can effectively prolong the battery's service life [43]. Urban rail transit systems combine high transport capacity and low station distance. Similarly, with electric vehicles, the frequent start-brake produces energy losses. The supercapacitor meets the energy management requirement of large capacity, long service life, and high power density, having the comprehensive value of application in different urban rail transit systems vehicles. A kind of trolley bus equipped with carbon/carbon organic supercapacitor was independently developed in Ningbo in 2017. The urban rail train itself carries a huge amount of kinetic energy when it runs. When the train slows down and stops at the station, the energy is converted into electrical energy and sent back to the grid through the electromagnetic braking of the driving motor. The traditional method releases the braking energy through the brake resistance, resulting in the waste of energy. Such trolley bus with $1500 \mathrm{~V}$ supercapacitor developed in Ningbo absorbs energy while braking, and then transmits the absorbed braking energy to the power grid, realizing the recovery and utilization of train braking energy and effectively avoiding energy waste caused by rising ambient temperature during the braking process [44].

\section{Strategy and Innovation Status Quo}

\subsection{National Innovative Capacity}

Innovation is primarily measured by the number of patent applications or licensing. Figure 6 shows the trend in the number of patents filed. In the 11 years from 2009 to 2020, there were 1363 domestic patent applications, including 975 invention patents, 370 utility models, 10 registration of designs, and 287 licensing agreements. Obviously, invention IP protection is becoming popular in the domestic sense, which shows that China's original innovation ability of supercapacitors is gradually increasing. 


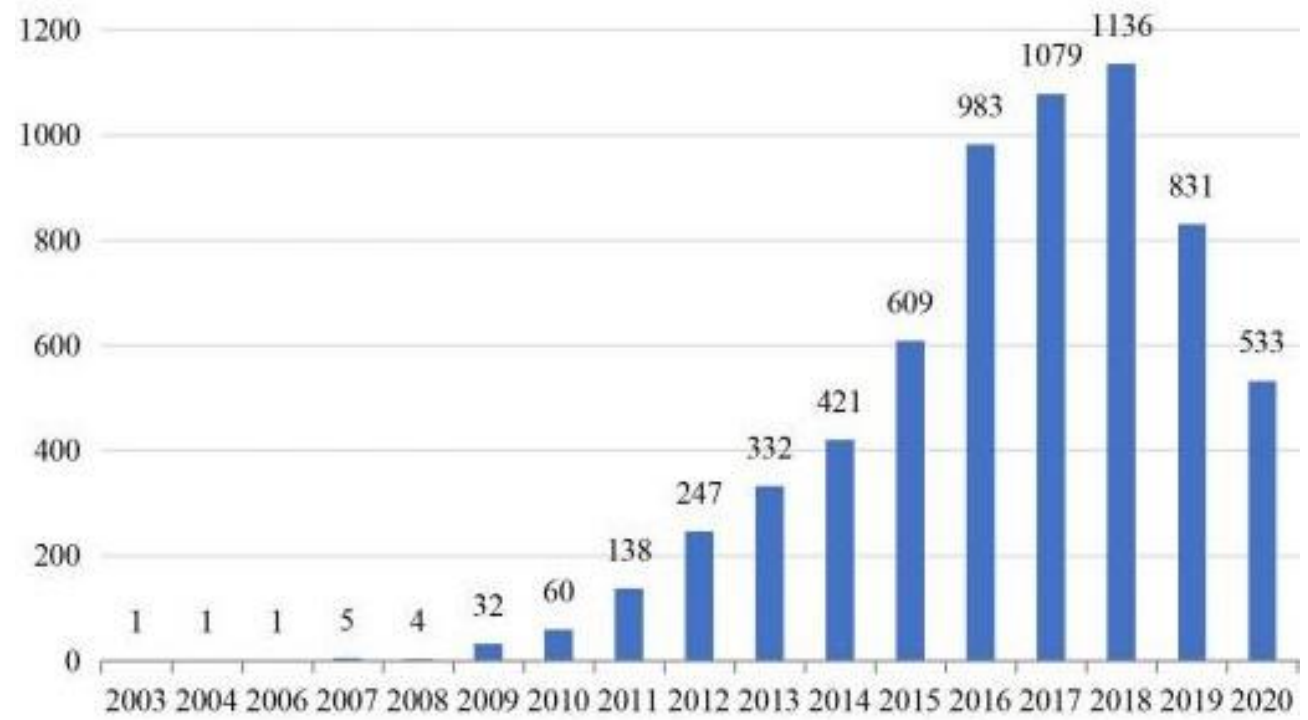

Figure 6. The total amount of patent application for supercapacitors in China since 2003.

Figure 7 shows the distribution of the patents. The proportions of the provinces whose science, technology, and economy are advanced, such as Jiangsu, Guangdong, Shanghai, Beijing, and Zhejiang, are all over $10 \%$, accounting for $68.26 \%$, over two-thirds of the total patents. Thus, the research and development ability of the domestic supercapacitor pivots on science, technology, and economy-developed provinces.

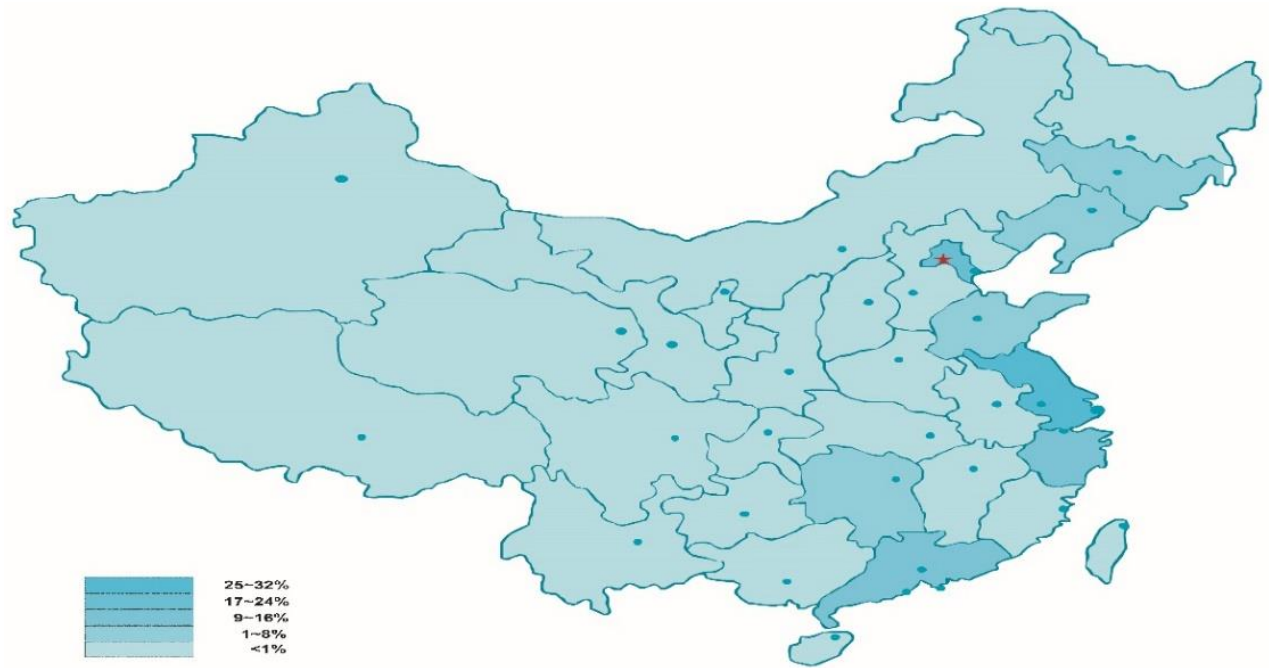

Figure 7. Distribution of the patents in China.

Figure 8 shows the ranking of the applicants and the inventors. The top ten applicants, with a total of 361 patents, accounts for $26.49 \%$ of the number of patents in China. The inventors featured in the top ten China rankings applied for 518 patents, as the ratio of 38 percent is close to 40 percent. So, the inventors and applicants who are ranked high contribute enormously to the supercapacitors. The whole industry is mainly powered by them. 


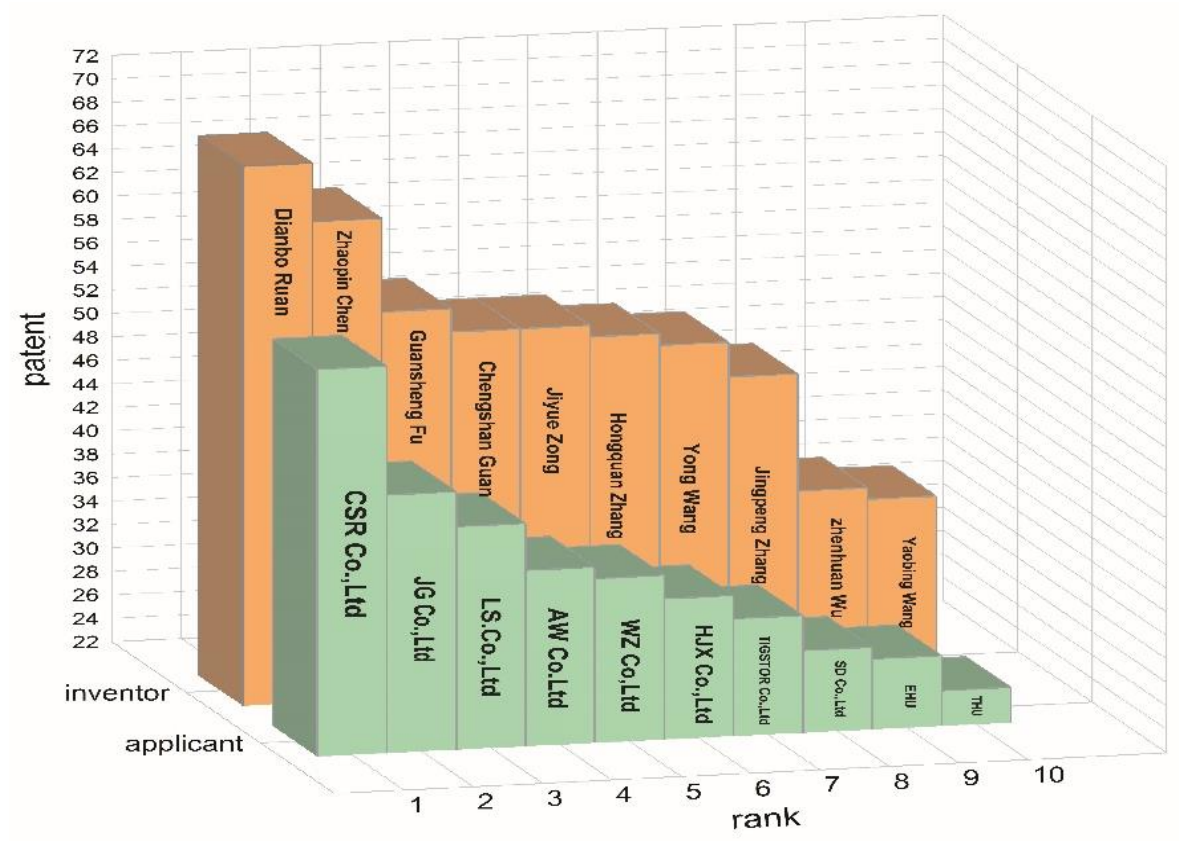

Figure 8. The top ten applicants and inventors in China.

From Figure 9a, it is clear that in the patent application countries, Japan, China, the United States, and South Korea, the application volume is larger. Among them, the number of patent applications in Japan was high before 2006 and showed a trend of steady rise. It reached a peak in 2006, and then the application speed slowed down or even showed a trend of decline, but the number of patients remained above 400 per year. Before 2006, the application trends of China, the United States, and the Republic of Korea were relatively similar, with slow growth and a small number each year. After 2006, although the patent application volume of the United States and the Republic of Korea increased somewhat, the growth rate was not large, and the overall trend fluctuated. China's patent applications show great changes, with the fastest growth rate and the largest change range. Among them, the annual growth rate between 2007 and 2012 is more than $30 \%$. In 2011, the annual application volume surpassed that of Japan, making China the country with the largest annual patent application volume. It can be predicted that, with the rapid growth in the social demand for new energy and the integration of the global market, more countries will participate in the future, and the annual patent application will remain at a high level. As can be seen from Figure 9b, Japan, China, the United States, and Korea are the main competitors, and their patent applications account for $83 \%$ of the total applications. Japan contributed the largest portion. Figure 9c shows that the supercapacitor market continued to expand from 2015 to 2020 in China, showing an upward trend. From 4.01 billion in 2015 to 118.3 billion in 2019 , it is expected to maintain a $30 \%$ growth rate in the next three years. The prospect of the supercapacitor market size will reach 15.2 billion in 2020 . Figure $9 \mathrm{~d}$ shows the demand for supercapacitors in different aspects, referring to transportation, industry, and new energy from 2014 to 2021. It indicates that transportation is still the largest proportion, such as electric bus and vehicle. At present, new energy vehicles produced for Chinese customers are mainly equipped with lithium batteries, but from the perspective of the entire life cycle, the future development potential of supercapacitors is unlimited. New energy contributes the smallest proportion, but supercapacitors can be used in many aspects of new energy, such as wind power, receiving converters, solar energy, solar light, etc. In the future, with the reform of China's energy framework, supercapacitors will be in an irreplaceable position for new energy. 
(a)

(b)

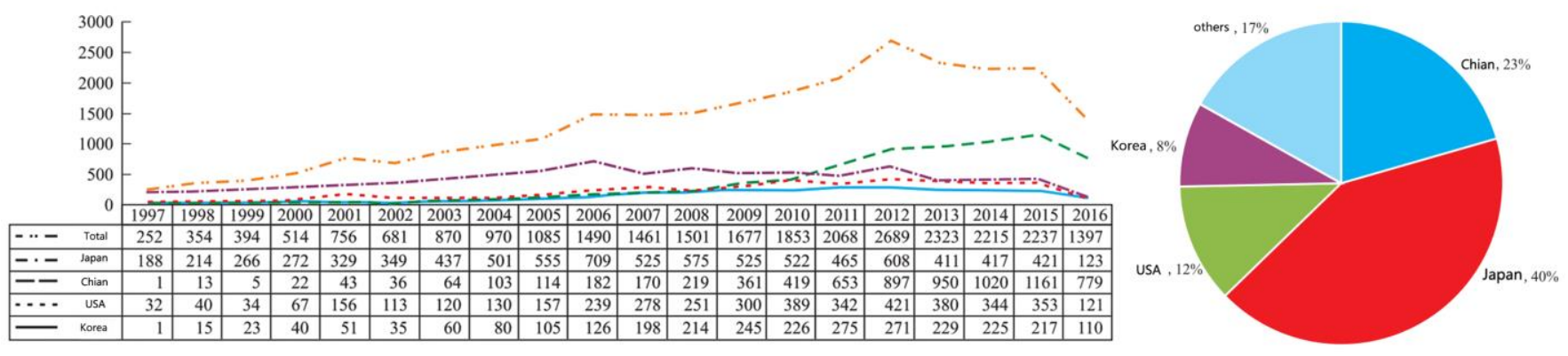

(c)

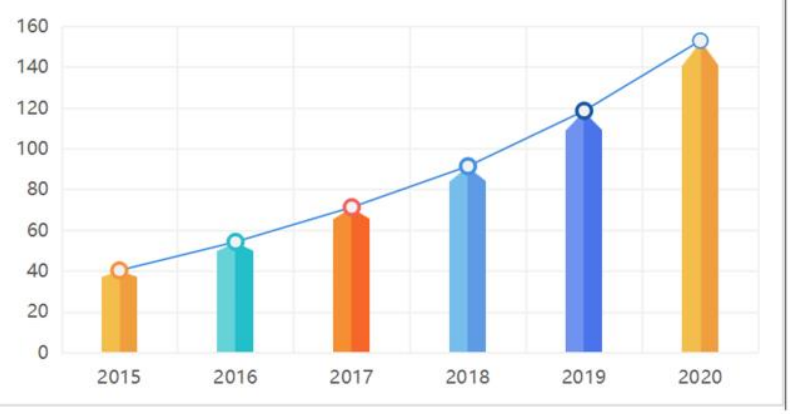

(d)

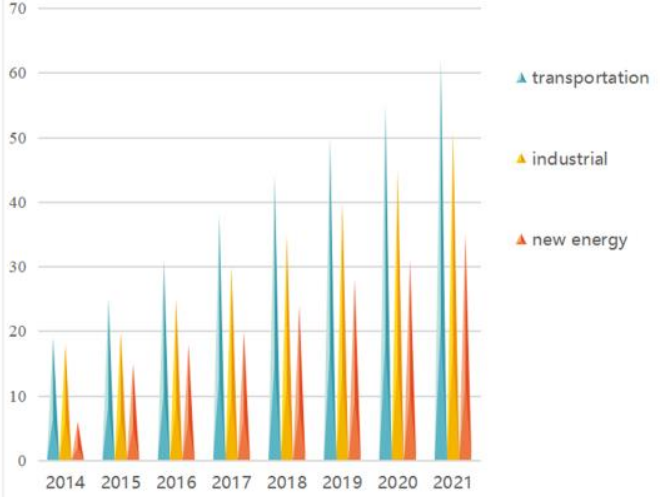

Figure 9. (a) Patent application trend in the field of supercapacitors. (b) Distribution of patent application country (region). (c) China supercapacitors market size forecast (CNY 100 million). (d) Subdivision product scale and forecast of supercapacitor in China.

\subsection{Policy Incentives}

The Chinese government has attached great importance to incentive policies for new energy and energy storage technology in recent years. In the key area of the current guidelines to the development of high technology industrialization, China clarifies the importance of developing large capacity electric energy and the application of the braking absorption equipment in urban rail trains. As an important element of power and electronic systems, the innovation and popularization of supercapacitors are of great significant for environmentally friendly and sustainable development. Supercapacitors have obvious advantages in electric vehicle applications. Energy-saving vehicles and new energy vehicles industry guidelines issued by the State Council emphasizes the strengthening of the key technologies R\&D of new energy vehicles, especially the development of new supercapacitors combined with batteries. The construction of new energy bus demonstration city will be beneficial to promote the iteration and maturity of supercapacitor on-board energy storage technology. Meanwhile, many local governments in China have introduced preferential policies to encourage the development of local supercapacitor industries. For example, the local government in Chaoyang City in Liaoning province issued several policies on supporting the infrastructure construction of the supercapacitor industry in October 2019. These policies can offer help to the enterprises and projects in terms of technology, investment, and finance support and so on. In December of the same year, the single-layer graphene film for the electrode of supercapacitors was volume manufactured in Chaoyang City, which can bring trillions in production value in the future combined with the upstream and downstream industries' production chain. In 2060, according to the forecast from the state grid of China, the per capita consumption of electricity will be about $8000 \mathrm{~kW} /$ year, so the total demand for electricity will be 14.5 trillion $\mathrm{kWh} /$ year, of which hydropower is expected to take up 1.5 trillion $\mathrm{kWh}$ and nuclear power, 1.6 trillion $\mathrm{kWh}$. Due to the instability of renewable energy, thermal power is estimated to retain 2 trillion $\mathrm{kWh}$. So, the demand for wind power and photovoltaic power generation needs to provide a total of 9.4 trillion $\mathrm{kWh}$, among which the estimated total installed capacity of wind 
power is 1.2 billion $\mathrm{kW}$ ( $2000 \mathrm{~h}$ per year), and photovoltaic is 3 billion $\mathrm{kW}$ ( $1500 \mathrm{~h}$ per year). Such a large photovoltaic grid connection will definitely cause a huge impact on the power grid. The instantaneous mismatch between energy supply and demand will lead to the instability of the voltage or frequency of the power. On the other hand, power generation, transmission and power sides were designed according to the rated voltage and frequency, which will lead to the damage of these power electric equipment. In addition, it may lead to regional power failure, such as the Texas power failure in the winter of last year. Therefore, with the input of a large number of unstable power sources, whether it is power generation, transmission or utilization, energy storage technology is essential. However, many energy storage technologies, such as flow batteries, pumped storage, compressed air, etc., struggle to meet such rapid response requirements. Currently, only supercapacitors can meet the demand for short-term high-frequency storage.

\subsection{Suggestions}

Although supercapacitor have become an indispensable part of hybrid electrochemical energy storage due to its many advantages, such as short-time efficient frequency modulation, long-cycle life, fast charging, etc., they are always overshadowed by batteries. The development of lithium-ion batteries, for example, has been boosted in recent years by heavy government subsidies and investor funding, making it easier to catch the world's attention on international racetracks. In contrast, it is difficult for supercapacitors to obtain strong financial support, and the progress and development of technology has been greatly restricted. Once supercapacitors make a breakthrough in technology, they will greatly promote the development of new energy industry and the achievement of carbon neutrality. The following suggestions are put forward:

(1) Strengthen research on new technologies for supercapacitors materials.

The key point to developing supercapacitors is to improve the energy density. In order to enhance the research level in China for SC-related applications, the development of electrode and diaphragm materials must be strengthened. As a backward country in the fields of supercapacitors, China is relatively weak in industrial technology research. Only by increasing the financial investment and stimulating the enthusiasm of industrial investment can it catch up with the advanced international level. The development of basic technology is a process of accumulation. The Chinese government should provide long-term investment and support to promote it.

(2) Develop energy storage technology according to practical demand

The application of supercapacitors in the energy storage system is still in the stage of development. Some applications, especially for electric power systems, still have great potential to achieve large-scale development in the future. China should further expand its application based on the actual demand, looking for the motivation and direction in practical application. China has a vast market and opportunities for supercapacitors. Once there is an insatiable demand, it will continue to promote technology and application to a higher level.

(3) Promote the demonstration and commercialization of energy storage technology

Supercapacitors identified as fast-emerging technologies have already been taken as the key developing field in China. In terms of policy support, China's incentive measures for supercapacitors are in their infancy, whether it is national key R\&D projects or funding from local government. Measures should be taken to ensure the effective development of the energy storage industry, especially to the whole industrial chain of supercapacitors. Technology and capital will be guided to the research and application of supercapacitors, and the enterprise-university-institute cooperation will be encouraged and promoted to improve the efficiency in transforming scientific research achievement into production technologies. 
(4) Enhance the cooperation in academic and industrial fields

The development of the supercapacitor industry grows out of the common progress of theory and applied field, and China has accumulated mature experience in the domestic applied field, which can provide truly valuable research directions. It can also make advanced research results create more kinds of applications. Besides the domestic collaboration, both the academic institutions and industrial enterprises should learn from the advanced technologies and solution of other countries in implementing the energy storage systems, introduce and digest them, and put them into effect by combining the practical demand in China.

\section{Conclusions and Prospects}

Supercapacitors have become increasingly attractive because of their higher energy density and specific high capacitance values, which are worth studying in-depth. They are widely used to improve the reliability and quality of power distribution of the smart grids, which can provide short-term power protection for the impact load of the power system. The paper elaborately summarizes the development status and policies of supercapacitors in China. It introduces the classification of the supercapacitors, compares the differences and the trend of different types of supercapacitors. The supercapacitors industry started late in China, and is still in its early stages. Chinese incentive policies for supercapacitors maintain in the guiding model, without the formulation of policies of promotion and application as of yet. This review presents some suggestions to ensure the effective development of supercapacitors. The key points are to achieve technological breakthroughs in processing the basic materials related to new supercapacitors, and develop the technologies combined with practical demand. The government should also vigorously promote the development of supercapacitor technology demonstration and commercialization to enhance domestic and international cooperation in academic and industrial fields. To realize the large-scale production and application of supercapacitors, it is necessary to find novel electrode materials with low cost that are environmentally friendly and have a long cycle life. With the maturity of solid-state electrolyte material technology, all-solid-state supercapacitors will have great achievements in the future.

In the coming decades, the development of supercapacitors will show an explosive growth trend. The use of supercapacitors may approach that of batteries in the future by breaking through key issues, such as energy density, which plays a significant role in the energy storage fields. Under the carbon neutral target, new energy generation is growing rapidly, and the Chinese supercapacitors market will find a good opportunity for development. In addition, with the increasing demand for flexible electronic devices, flexible wearable supercapacitors will occupy a large share in the Chinese market and even the world market.

Author Contributions: Writing-original draft and investigation, Y.Y.; funding acquisition and resources, Y.H.; visualization, W.J.; writing-review Y.Z.; editing, Y.X.; supervision, A.M.A. All authors have read and agreed to the published version of the manuscript.

Funding: This research was funded by the National Key R\&D Program in China (No. 2017YFC02102021) and supported by the Chinese Academy of Sciences Network Security and Information Special Project and Fundamental Research Funds for the Central Universities (2018MS133).

Institutional Review Board Statement: Not applicable.

Informed Consent Statement: Not applicable.

Data Availability Statement: Not applicable.

Acknowledgments: The authors acknowledge the support provided by Yuanxuan Zhang from University of Chinese Academy Sciences and the useful discussion with Yunpeng Liu and Xiangwu Yan from Hebei Key Laboratory of Distributed Energy Storage and Microgrid.

Conflicts of Interest: The authors declare no conflict of interest. 


\section{References}

1. Li, M.; Patiño-Echeverri, D. Estimating benefits and costs of policies proposed in the 13th FYP to improve energy efficiency and reduce air emissions of China's electric power sector. Energy Policy 2017, 111, 222-234. [CrossRef]

2. Zou, C.; Zhang, L.; Hu, X.; Wang, Z.; Wik, T.; Pecht, M. A review of fractional-order techniques applied to lithium-ion batteries, lead-acid batteries, and supercapacitors. J. Power Sources 2018, 390, 286-296. [CrossRef]

3. Huang, S.; Zhu, X.; Sarkar, S.; Zhao, Y. Challenges and opportunities for supercapacitors. APL Mater. 2019, 7, 100901. [CrossRef]

4. Zhang, H.; Sun, C. Cost-effective iron-based aqueous redox flow batteries for large-scale energy storage application: A review. J. Power Sources 2021, 493, 229445. [CrossRef]

5. Simon, P.; Gogotsi, Y. Materials for electrochemical capacitors. Nat. Mater. 2008, 7, 845-854. [CrossRef] [PubMed]

6. Zhang, L.; Hu, X.; Wang, Z.; Sun, F.; Dorrell, D. A review of supercapacitor modeling, estimation, and applications: A control/management perspective. Renew Sust. Energ. Rev. 2018, 81, 1868-1878. [CrossRef]

7. Poudel, M.; Kim, H. Confinement of $\mathrm{Zn}-\mathrm{Mg}$-Al-layered double hydroxide and $\alpha-\mathrm{Fe}_{2} \mathrm{O}_{3}$ nanorods on hollow porous carbon nanofibers: A free-standing electrode for solid-state symmetric. Chem. Eng. J. 2022, 429, 132345. [CrossRef]

8. Zhu, L.; Hao, C.; Zhou, S.; Wang, X.; Zhou, T.; Guo, Y. Ternary $\mathrm{ZnO} / \mathrm{Co}_{3} \mathrm{O}_{4} / \mathrm{NiO}$ inherited layered core-shell structure from a double template for high performanced supercapacitor. J. Mater. 2021, 7, 708-720. [CrossRef]

9. Zhu, X.; Li, X.; Tao, H.; Li, M. Preparation of $\mathrm{Co}_{2} \mathrm{Al}$ layered double hydroxide nanosheet $/ \mathrm{Co}_{2} \mathrm{Mn}$ bimetallic hydroxide nanoneedle nanocomposites on nickel foam for supercapacitors. J. Alloy. Compd. 2021, 851, 156868. [CrossRef]

10. Wang, W.; Song, X.; Gu, C.; Liu, D.; Liu, J.; Huang, J. A high-capacity $\mathrm{NiCo}_{2} \mathrm{O}_{4} @$ reduced graphene oxide nanocomposite Li-ion battery anode. J. Alloy. Compd. 2018, 741, 223-230. [CrossRef]

11. Chavan, H.; Hou, B.; Ahmed, A.; Jo, Y.; Cho, S.; Kim, J.; Pawar, S.; Cha, S.; Inamdar, A.; Im, H.; et al. Nanoflake NiMoO 4 based smart supercapacitor for intelligent power balance monitoring. Sol. Energy Mater. Sol. Cells 2018, 185, 166-173. [CrossRef]

12. Zhou, J.; Wu, T.; Han, Y.; Aryana, S. Fabrication of Mn-Ce bimetallic oxides as electrode materials for supercapacitors with high performance. J. Electron. Mater. 2021, 50, 2725-2735. [CrossRef]

13. Han, Y.; Zhou, J.; Wang, L.; Xing, K.; Xue, Z.; Jiao, Y.; Pang, Y. Redox-active nanostructure electrode of Mn/Ni bimetal organic frameworks anchoring on multi-walled carbon nanotubes for advanced supercapacitor. J. Electroanal. Chem. 2021, 882, 114993. [CrossRef]

14. Jiao, Y.; Han, Y.; Pang, Y.; Zhou, J.; Qi, X.; Liu, Y. The plate-like hexagonal Ni-Fe-Sr layered double hydroxides as advanced electrodes for electrochemical energy storage. J. Electro. Mater. 2020, 49, 1043-1050. [CrossRef]

15. Song, L.; Han, Y.; Guo, F.; Jiao, Y.; Li, Y.; Liu, Y.; Gao, F. Mesoporous nickel-based zeolite capsule complex with $\mathrm{Fe}_{3} \mathrm{O}_{4}$ as electrode for advanced supercapacitor. J. Nanomater. 2018, 1, 9813203. [CrossRef]

16. Han, Y.; Li, L.; Liu, Y.; Li, X.; Qi, X.; Song, L. Fabrication of strontium bismuth oxides as novel battery-type electrode materials for high-performance supercapacitors. J. Nanomater. 2018, 1, 5078473. [CrossRef]

17. Yang, Z.; Wang, Y.; Dai, Z.; Lu, Z.; Gu, X.; Zhao, H.; Sun, G.; Lan, W.; Zhang, Z.; Pan, X.; et al. Nature of improved double-layer capacitance by $\mathrm{KOH}$ activation on carbon nanotube-carbon nanofiber hierarchical hybrids. Carbon 2019, 146, 610-617. [CrossRef]

18. Zhang, S.; Yin, B.; Liu, X.; Gu, D.; Gong, H.; Wang, Z. A high energy density aqueous hybrid supercapacitor with widened potential window through multi approaches. Nano Energy 2019, 59, 41-49. [CrossRef]

19. González, A.; Goikolea, E.; Barrena, J.; Mysyk, R. Review on supercapacitors: Technologies and materials. Renew. Sust. Energy Rev. 2016, 58, 1189-1206. [CrossRef]

20. Pandolfo, A.G.; Hollenkamp, A.F. Carbon properties and their role in supercapacitors. J. Power Sources 2006, 157, 11-27. [CrossRef]

21. Shown, I.; Ganuly, A.; Chen, L.; Chen, K. Conducting polymer-based flexible supercapacitor. Energy Sci. Eng. 2015, 3, 2-26. [CrossRef]

22. Li, B.; Huang, Y.; Cheng, P.; Liu, B.; Yin, Z.; Lin, Y.; Li, X.; Wang, M.; Cao, H.; Wu, Y. Upgrading comprehensive performances of gel polymer electrolyte based on polyacrylonitrile via copolymerizing acrylonitrile with $\mathrm{N}$-vinylpryrrolidone. Electrochim. Acta 2019, 320, 134572. [CrossRef]

23. Zhuo, H.; Hu, Y.; Chen, Z.; Zhong, L. Cellulose carbon aerogel/PPy composites for high-performance supercapacitor. Carbohydr Polym. 2019, 215, 322-329. [CrossRef]

24. Awang, N.; Nasir, A.; Yajid, M.; Jaafa, J. A review on advancement and future perspective of 3D hierarchical porous aerogels based on electrospun polymer nanofibers for electrochemical energy storage application. J. Environ. Chem. Eng. 2021, 9, 105437. [CrossRef]

25. Liu, J.; Weng, W.; Xie, H.; Luo, G.; Li, G.; Sun, W.; Ruan, C.; Wang, X. Myoglobin- and hydroxyapatite-doped carbon nanofibermodified electrodes for electrochemistry and electrocatalysis. ACS Omega 2019, 4, 15653-15659. [CrossRef]

26. Zhang, H.; Bhat, V.; Gallego, N.; Contescu, C. Thermal treatment effects on charge storage performance of graphene-based materials for supercapacitors. ACS Appl. Mater. Interfaces 2012, 4, 3229-3246. [CrossRef]

27. Zhang, Q.; Zhang, Y.; Gao, Z.; Ma, H.; Wang, S.; Peng, J.; Li, J.; Zhai, M. A facile synthesis of platinum nanoparticle decorated graphene by one-step $\gamma$-ray induced reduction for high rate supercapacitors. J. Mater. Chem. C 2013, 1, 321-328. [CrossRef]

28. Zheng, S.; Yang, J.; Yu, S. How renewable energy technological innovation promotes renewable power generation: Evidence from China's provincial panel data. Renew. Energy 2021, 177, 1394-1407. [CrossRef]

29. Wang, F.; Wu, X.; Yuan, X.; Liu, Z.; Zhang, Y.; Fu, L.; Zhu, Y.; Zhou, Q.; Wu, Y.; Huang, W. Latest advances in supercapacitors: From new electrode materials to novel device designs. Chem. Soc. Rev. 2017, 46, 6816-6854. [CrossRef] 
30. Gonella, G.; Backus, E.; Nagata, Y.; Bonthuis, D.; Loche, P.; Schlaich, A.; Netz, R.; KÜhnle, A.; McCrum, I.; Koper, M.; et al. Water at charged interfaces. Nat. Rev. Chem. 2021, 5, 466-485. [CrossRef]

31. Yadav, N.; Yadav, N.; Hashmi, S.A. Ionic liquid incorporated, redox-active blend polymer electrolyte for high energy density quasi-solid-state carbon supercapacitor. J. Power Sources 2020, 451, 227771. [CrossRef]

32. Fu, C.; Kuang, Y.; Huang, Z.; Huang, Z.; Wang, X.; Yin, Y.; Chen, J.; Zhou, H. Supercapacitor based on graphene and ionic liquid electrolyte. J. Solid State Electrochem. 2011, 15, 2581-2585. [CrossRef]

33. Gao, Y.; Ai, Q.; Yousif, M.; Wang, X. Source-load-storage consistency collaborative optimization control of flexible DC distribution network considering multi-energy complementarity. Int. J. Electr. Power Energy Syst. 2019, 107, 273-281. [CrossRef]

34. Cui, W.; Li, J.; Xu, W.; Güneralp, B. Industrial electricity consumption and economic growth: A spatio-temporal analysis across prefecture-level cities in China from 1999 to 2014. Energy 2021, 222, 119932. [CrossRef]

35. Han, Y.; Pu, Y.; Li, Q.; Fu, W.; Chen, W.; You, Z.; Liu, H. Coordinated power control with virtual inertia for fuel cell-based DC microgrids cluster. Int. J. Hydrogen Energy 2019, 44, 25207-25220. [CrossRef]

36. Yang, B.; Wang, J.; Wang, J.; Shu, H.; Li, D.; Zeng, C.; Chen, Y.; Zhang, X.; Yu, T. Robust fractional-order PID control of supercapacitor energy storage systems for distribution network applications: A perturbation compensation based approach. J. Clean. Prod. 2021, 279, 123362. [CrossRef]

37. Nazir, M.S.; Abdalla, A.N.; Wang, Y.; Chu, Z.; Jie, J.; Tian, P.; Jiang, M.; Khan, I.; Sanjeevikumar, P.; Tang, Y. Optimization configuration of energy storage capacity based on the microgrid reliable output power. J. Energy Storage 2020, $32,101866$. [CrossRef]

38. Yan, Q.; Bo, Q.; Jingjie, Y.; Yunfei, M.; Bingqing, G. Frequency Control Strategy of Hybrid Energy Storage System for Microgrid Based on Frequency Hysteretic Loop. Energy Procedia 2016, 103, 328-332. [CrossRef]

39. Ma, H.; Zhang, Y.; Shen, M. Application and prospect of supercapacitors in Internet of Energy (IOE). J. Energy Storage 2021, 44, 103299. [CrossRef]

40. Yang, B.; Wang, J.; Sang, Y.; Yu, L.; Shu, H.; Li, S.; He, T.; Yang, L.; Zhang, X.; Yu, T. Applications of supercapacitor energy storage systems in microgrid with distributed generators via passive fractional-order sliding-mode control. Energy 2019, 187, 115905. [CrossRef]

41. Tan, Q.; Ding, Y.; Zheng, J.; Dai, M.; Zhang, Y. The effects of carbon emissions trading and renewable portfolio standards on the integrated wind-photovoltaic-thermal power-dispatching system: Real case studies in China. Energy 2021, $222,119927$. [CrossRef]

42. Chen, H.; Gao, X.-Y.; Liu, J.-Y.; Zhang, Q.; Yu, S.; Kang, J.-N.; Yan, R.; Wei, Y.-M. The grid parity analysis of onshore wind power in China: A system cost perspective. Renew. Energy 2020, 148, 22-30. [CrossRef]

43. Xie, D.; Liu, M.; Xu, L.; Lu, W. Bi-level programming approach for coordinated configuration of distributed generations and automation devices in distribution networks. Int. J. Electr. Power Energy Syst. 2021, 133, 107210. [CrossRef]

44. Lin, J.; Niu, J.; Li, H.; Atiquzzaman, M. A Secure and Efficient Location-based Service Scheme for Smart Transportation. Future Gener. Comput. Syst. 2019, 92, 694-704. [CrossRef] 